\title{
Creation theActivity Modelsfor the New Generation Thai Teacher's Characteristics Conserved the Environments and the LivelihoodFollowedthe Sufficient Economy Philosophy ofthe Frist-Year Students, Faculty of Education at RattanakosinRajabhat University
}

\author{
SommaiPavaboot \\ ${ }^{a}$ Faculty of Education, SuanSunandhaRajabhat UniversityBangkok Thailand \\ sommai.pa@ssru.ac.th
}

Article History: Received: 10 November 2020; Revised 12 January 2021 Accepted: 27 January 2021; Published online: 5 April 2021

\begin{abstract}
Learners realized how to protect,conserve the natural resources and value environments. Their livelihoodfollowed thesufficient economy philosophyand realized to their conscious for changing the globalizations. They must follow the rules of the professional education in 2013 for the self- management standard. The purpose of this research article was to study results of the experiments on creation theactivity models for the new generation Thai teacher's characteristics conserved the environments and the livelihoodfollowed thesufficient economy philosophy to the first-year students, faculty of education at RattanakosinRajabhat Universityand the different between before and after experiments.This research was used by Randomized Control Group Pretest- Posttest Design.Statistical hypothesis testing wast - test for Dependent Sample andt-test for Independent Sample: Difference Scores.This researchwas found that after the experiment was the higher scores than before experiment. It issignificant at .05. Further Suggestions of this research showed that the activities should be continuously practiced by the learners themselves and adjust to their worthy lives. The teacher's dutiesmeans providing the facilities, suggestions, inspiration, praise, complementary, making goodness, supporting positive thinking and esteem to Thai social activities and Thai cultures.
\end{abstract}

Keywords: Activity Models, New Generation Thai Teacher's Characteristics, Conserved the Environments, Sufficient Economy Philosophy,RattanakosinRajabhat University

\section{Introduction}

Rajabhat Universities' duties, the faculty of education, create and develop good capability teachers. The new generation Thai teacher'scharacteristics conserve the environments and thelivelihood follows thesufficient economy philosophyof thefirst-year students, faculty of education at RattanakosinRajabhat University. They will be the most important persons to develop Thailand and ASEAN EconomicCommunity(AEC).Rajabhat Universities' duties must support, realize, protect the environments and adjust to their lives the following sufficient economy philosophy. Besides, their duties must create thecreative knowledge, cognition, understanding, introductions, ideals, subconscious, practical activities, learning and creativelycritical thinking to learners. The new generation Thai teacher'scharacteristics must have good knowledge, cognition, subconscious,morals and ethics and know how to be alive tofollow thesufficient economy philosophy and conserve the environments. Furthermore, they are able to adjust to live with the other people in diverse cultures. They are able to create their knowledge, cognition and experiences to transfer to learners. The learners are able to develop themselves. ProjectBase Learning (PBL)and Contemplative EducationActivitywerecreated to the new generation Thai teacher's characteristicswhowere learned by themselves about emotion, feeling, creative thinking and believe for the realization to value objectives, affection, kindness, conscious mind to participation, transferring to the various knowledge and cognition to adjust to be perfect lives.

The researcher studied theactivity models for the new generation Thai teacher'scharacteristics conserve the environment and the livelihood followed thesufficient economy philosophyto the first-year students, faculty of education at RattanakosinRajabhat University. This activity wastheProject-Based Learning (PBL)Activity: Conserve the environment and the livelihood followed thesufficient economy philosophyand the Contemplative Education Activity. Preparation to thelearners were developed to Thailand and ASEAN EconomicCommunity (AEC) in the $21^{\text {st }}$ century.

\section{Research Objectives}

The purpose of this research article was to study results of the experiments on creation theactivity models for the new generation Thai teacher's characteristics conserved the environments and the livelihoodfollowed 
thesufficient economy philosophy to the first-year students, faculty of education at RattanakosinRajabhat Universityand the different between before and after experiments.

\section{Research Hypothesis}

The results of experiments (Creation theactivity models for the new generation Thai teacher's characteristics conserved the environments and the livelihoodfollowed thesufficient economy philosophy to the first-year students, faculty of education at RattanakosinRajabhat University) were the following items:

After using this activity modelswas foundthat afterexperiments were higher scores than before experiments.

4.

\section{Technical Terms}

1. The new generation Thai teacher's characteristics conserve the environmentsmeans the knowledge, understanding, cognition, feeling, realization, environmental conservation. They are able to use the natural resources for long run by realizing the most advantageswhich consisted of 1)Savingand usingenergy means the activities for using the less energy and essential energy. Moreover, the research studied how to save the most usefulenergy, 2)Participation in cultivating the forest means participants must be willing to cultivate a lot of trees to be the forests. The learners participated the activities to cultivate the mangrove forest for three days and two nights, 3)Campaign global warming means there aremany activities such as turning off the lights after finishing activities, saving water, riding bicycle instead of cars, walking short distances and growing the trees.

2. The new generation Thai teacher's characteristics for the livelihood tofollow the sufficient economy philosophymeans the livelihood should be middle lines including the essential impactions and changing the world the following items:1)Moderate daily living means the livelihood is sufficient, middle and essential to oneself, society, environments including diverse cultures in each local.The daily livelihood should be moderate and should not be afflicted oneself and the other persons.2)Rationality means decision to do something which are correct morals, ethics, legal, academicbackground, critical thinking carefullyand diverse good culture.The learnersshould think carefully to effect the various functions which may be happened in the future.3)Self-immunity means preparation from the impactions to changing in economic, society, environments and various culturesare be able to adjust themselves immediately.

5. 3.The activity models for the new generation Thai teacher's characteristics of thefirst-year students, faculty of education at RattanakosinRajabhat University was divided into two activities the following items:1)Contemplative Education Activityhas five steps the following items:The first step: Survey of thinking, peaceful mind and preparationoneself for learning. Activity: Kaoshingki dancing and singing a song such as the NationalAnthem, the Thai Royal Anthem, Teacher song, March song and meditation.The second step: Open mindand encourage to thinking. Activity: Making the questions to transfer internal and external thinking by themselves.The third step: Exchangingthe knowledge, and Activity:Listening to the dialogues aesthetically and exchangingonelanother from small groups to big groups, The fourth step: Revision and conclusion, and Activity:Ideas and deliberate concepts oneself. The fifth step: Report the results, and Activity:Creative thinking, conclusion and report the results for their creative thinking and knowledge to the other persons.

3. Project-BasedLearning Activity (PBL)is consist of five steps the following items:The first step: Study the problems, The second step: Plan for practicing, The third step: Followplanning and learning while they are practicing, The fourth step: Evaluate the project, and The fifth step: Presentthe project.

\section{Research Method}

This research was an experimental developmentthe following research.

\section{Population and sampling group}

Population was 1,500first-year students, faculty of education atRattanakosinRajabhat University the following universities: SuanSunandhaRajabhat university, PranakornRajabhat university, BansomdejchaoprayaRajabhat university, ChankasemRajabhatUniversity and DhonburiRajabhatUniversity.Sampling group was 100 first-year students, faculty of education atRattanakosinRajabhat University the following universities: SuanSunandhaRajabhat university(20 persons), PranakornRajabhat university (20 persons), BansomdejchaoprayaRajabhat university (20 persons), ChankasemRajabhat university (20 persons) and DhonburiRajabhat university (20 person) who had studied professionalteaching subject (EDU 1102) and the control group (100 persons) who studied this subject.Time for this Research: The first semester, academic year in 2017.

Variable in the Research consisted of 1) Independent variablewas the firstly, the Contemplative Education Activityfor reinforcement to the new generation Thai teacher'scharacteristics and the livelihood followed the 
sufficient economy philosophy. The secondly, the Project-Based Learning Activity (PBL) for the new generation Thai teacher's characteristics conserved the environments.2) Dependent variable was consist of reinforcement to be the new generation Thai teacher's characteristics the following items:1) Environmental conservation, 2) Livelihood followedthe sufficient economy philosophy.

\section{Instrumentation of Research}

1) Instrumentation of research was consist of two activities the following items: Contemplative Education ActivityandProject-Based Learning Activity (PBL).2) Data collection was 1) questionnaires: the new generation Thai teacher's characteristics conserved the environments and the livelihood followed the sufficient economy philosophy, 2) Observation and Behavior Record, and 3) Evaluation from real situations.

Making Instrumentation of Researchwas consist of two activities the following items:

\section{Contemplative Education Activity}

There were five specialists to check the evaluation and Index of Item - Objective Congruence (IOC). Scores of Index of Item, Objective Congruence (IOC) from five specialistswerebetween4.20and 5.00 to be the most appropriate andIndex of Item - Objective Congruence(IOC)wasbetween 0.80and 1.00 which had to be evaluated by five specialists' advices. Then, this testing couldbe used one more with a new group. After that, it will be able to use the next research.

\section{Project-BasedLearning Activity (PBL)the Environmental Conservation}

There were five specialists to check the evaluation and Index of Item - Objective Congruence (IOC). Scores of Index of Item, Objective Congruence (IOC) from five specialistswere between 4.20and 5.00 to be the most appropriate scores andIndex of Item - Objective Congruence (IOC) was between 0.80 and1.00 whichhad to be evaluated by five specialists' advices. Then, this testing couldbe usedone more with a new group. After that, it will be able to use the next research.

\section{The questionnaire:}

The new generation Thai teacher's characteristics for the livelihood followed the sufficient economy philosophymeans testing about situations and each testing situation has 3o items. This questionnaire has 60 items bythe five specialists to check the measurement and Index of Item - Objective Congruence (IOC). Index of Item Objective Congruence ( IOC) was between 0.80 and 1.00. Difficultywas between 0.20 and 0.80 . Then, discrimination was 0.20 up by K-R20.(PhuangratThaweerat, 2000)

\section{Observation and Behavior Record:}

The new generation Thai teacher's characteristicsconserved the environments and the livelihood followed the sufficient economy philosophy. All of them were evaluated by the five specialists. They found that Index of Item Objective Congruence (IOC) was between 0.80 and 1.00. It could be used with observation and behavior record.

\section{Evaluation from real situations:}

The new generation Thai teacher's characteristics conserved the environments and the livelihood followed the sufficient economy philosophy. Theseevaluations from real situations wereevaluatedby scoring rubrics which were divided into three scales: excellent, good and fair. These evaluations were evaluated by the five specialists. They found thatIndex of Item - Objective Congruence (IOC) was between 0.80 and 1.00 which was able to be evaluated the research.

\section{Experimentation}

This research was an Experimental Developmentby using experimentation which was between an experimental group and a control group by randomized control grouppretest and posttest design the following items: (Kerlinger, F.N. and Lee, H.B., 2000).

\section{Before experimentation}

was usedby testing: the new generation Thai teacher's characteristicsconserved the environments and the livelihood followed the sufficient economy philosophywith thefirst-year students, faculty of education,RattanakosinRajabhat University. There were 100 persons in the first semester in 2017.Then, the researcher kept these scores to be the scores of pretest. 


\section{Experimentation}

\section{The first times}

The learners participated theContemplative Education Activity: the new generation Thai teacher's characteristicsconserved the environments and the livelihood followed the sufficient economy philosophy. There were 11 times the following activities:

The first activity: Orientation

The second activity:Livelihood follows the Sufficient Economy Philosophy (Middle Line)

The third activity: Environmental conservation(Saving and using energy) The fourth activity:The knowledge with good teacherexchangecamp (Good teachers must be middle line, save and use the most worthy energy) three days andtwo nights

The fifth activity:Livelihood follows the Sufficient EconomyPhilosophy (Rationality)

The sixth activity:Environmental conservation (Participation to Cultivate the Forests)

The seventh activity: Follow Dad's Footsteps Camp, Exchange the Knowledge with Philosopher and Participate to Cultivate the Forests (three days and two nights).

The eighth activity: Livelihood follows the Sufficient EconomyPhilosophy (Self-Immunity)

The ninth activity:Environmental conservation (Champaign Gobble warming)

The tenth activity: The Knowledge with Good Teachers ExchangeCamp (Self-Immunity and Champaign Gobble warming) three days and two nights

The eleventh activity: Post training

\section{The second times}

The learners participated theProject-Based Learning Activity (PBL): the new generation Thai teacher's characteristicsconserved the environments andthe livelihood followed the sufficient economy philosophy. There were two projectsthe followingitems:

1. The Environmental Conservation and the Livelihood followed the Sufficient Economy Philosophy.

2. The Community Services Project was divided into the following two projects: Academic Camp and the livelihood followed the sufficient economy philosophy. Academic Camp meansseniors, who participated the Environmental Conservation, transferred their knowledge to juniors.Furthermore, the livelihood followed the sufficient economy philosophy to participate with the professionalteaching, faculty of education,RattanakosinRajabhat University, to the developing schools in Bangkok and suburbs in the first semester, academic year 2018. There were six times and each times was one day.

The third times: The students practiced to follow each project.

The fourth times: The students presented the projects.

\section{After Experimentation}

After experimentation had finished for one week, the control group was evaluatedthe questionnaires:the new generation Thai teacher's characteristicsconserved the environments and the livelihood followed the sufficient economy philosophy were as same as the last one. This testing scores werekept for posttest.

\section{Results}

The results of comparison: the new generation Thai teacher's characteristicsconserved the environments and the livelihood followed the sufficient economy philosophythefirst-year students, faculty of education, RattanakosinRajabhat University the following tables: 
Table 1 Comparison of the average of the new generation Thai teacher's characteristicsconserved the environments of the control group between before and after experimentations.

\begin{tabular}{|c|c|c|c|c|c|c|}
\hline Experimentation & $\mathbf{n}$ & $\overline{\mathrm{X}}$ & S.D. & $t$ & df & p-value \\
\hline $\begin{array}{c}\text { Before } \\
\text { experimentations }\end{array}$ & 100 & 16.26 & 3.14 & \multirow{3}{*}{28.12} & \multirow{3}{*}{99} & \multirow{3}{*}{$.05 *$} \\
\hline & & & & & & \\
\hline $\begin{array}{c}\text { After } \\
\text { experimentations }\end{array}$ & 100 & 26.06 & 1.58 & & & \\
\hline
\end{tabular}

* significant at .05

From the first table, the results of comparison were different scores:the new generation Thai teacher's characteristicsconserved the environments of the control group between before and after experimentation the Project-Based Learning (PBL). The scores were significantly at .05 the following hypothesis after they had participated the activities the environmental conservation. The scoresafter experimentation were higherthan before experimentations.

Table 2Comparison of the average of the new generation Thai teacher's characteristics, the livelihood followed the sufficient economy philosophy of the control group between before and after experimentations.

\begin{tabular}{ccccccc}
\hline Experimentation & $\mathbf{n}$ & $\overline{\mathrm{X}}$ & S.D. & $\mathbf{t}$ & df & p-value \\
\hline $\begin{array}{c}\text { Before } \\
\text { experimentations }\end{array}$ & 100 & 15.91 & 2.81 & & & \\
$\begin{array}{c}\text { After } \\
\text { experimentations }\end{array}$ & 100 & 26.98 & 1.32 & & 99.07 & $.05^{*}$ \\
\hline \hline
\end{tabular}

* significant at .05

From the second table, the results of comparison were different scores(the new generation Thai teacher characteristics).The livelihood followed the sufficient economy philosophy of the control group between before and after experimentation. The scores were significantly at .05 the following hypothesisafter they had participated the activities the environmental conservation. The scoresafter experimentation were higher than before experimentation.

\section{Discussion}

The study of the new generation Thai teacher's characteristics and the livelihood followed the sufficient economy philosophy thefirst-year students, faculty of education,RattanakosinRajabhat University the following items: The new generation Thai teacher's characteristicsconserved the environments. After they had participated the Project-Based Learning Activity (PBL), their scores were higher than before experimentation. The results of scores were indicated the Project-Based Learning Activity(PBL) thatcould be created the self-conscious. The learners could protect, look after, conserve the natural resources, saving and using the most useful energy by themselves. In the $21^{\text {st }}$ century, the teachers will be designersand advisors who will design the knowledge, suggestions, and providingthe facilitate to the learners. The Project-Based Learning Activity ( PBL) is very appropriate because of a good working system and a science process. They could participate with the other people better.Theteachers' dutieswere only suggestion, reinforcement and to be a consultantfor solving the problems. These results of research were same as Hargis's concept (2005). The new generation Thai teacher's characteristics for thelivelihood followed thesufficient economy philosophy.After they had participatedthe Contemplative Education Activity. Their scores were higher than before experimentation whenthey had participated the activity.The results of scores were indicated theContemplative Education Activityto support them. The learners'thelivelihood could follow thesufficient economy philosophy.VichanPanich(2007)mentioned the processing of the learning oneself was consists of deep listening to the contemplations and meditation. It was transferred to be transformative learning which was become obligingness to adjust the daily live. TheContemplative Education Activity made the learners be applied to be the sufficientlives including selfimmunity, changing the society, environments and various cultures. Furthermore, ChanchaleeMapudh (2017) mentionedthe livelihood followed the sufficient economy philosophy forthe college students. It was found that the livelihood followed the sufficient economy philosophy which wasincluded healthy, dressing and expenses. All of them are in the middle levels. 


\section{Conclusions}

The new generation Thai teacher'scharacteristics must have good knowledge, cognition, subconscious,morals and ethics and know how to be alive tofollow thesufficient economy philosophy and conserve the environments. In addition, they are able to adjust to live with the other people in diverse cultures. They are able to create their knowledge, cognition and experiences to transfer to learners. The learners are able to develop themselves. The results of comparison were different scores:the new generation Thai teacher's characteristicsconserved the environmentsand the livelihood followed the sufficient economy philosophy thefirst-year students, faculty of education, RattanakosinRajabhat University.The scores after experimentation was higher than the scores before experimentation which was significant at.05. From the result can be interpreted that knowledge was transferred to be transformative learning which was become obligingness to adjust the daily live. TheContemplative Education Activity made the learners be applied to be the sufficientlives including self-immunity, changing the society, environments and various cultures.

\section{Recommendations}

1.TheContemplative Education Activityisimportant to the teachers who will be leaders to their learners. They should havea lot of experiences from the various activities which can be adjusted to their daily lives in the changing social and world.

2.TheProject-Based Learning Activity (PBL) should be continuously practiced by their doing and by doing themselves andavailable practices with oneself. They are able to applyfor all activities to their livelihood to transfer to be perfect humanity..

\section{References}

ChanchaleeMapudh. (2017). Students' Ways of Life with the Philosophy Sufficiency Economy in Higher Education. Journal of Education Burapha University. Vol. 28 No. 1 January - April 2017. page 28-40.

Hargis, J. (2005). Collaboration, Community and Project-Based Learning - Does It Still Work Online?. Instructional Media, 32(2).

Kerlinger, F.N. and Lee, H.B. (2000). Foundations of Behavioral Research. 4th Edition. United Kingdom: Cengage Learning.

PhuangratThaweerat. (2000) . Research Methods in Behavioral Sciences and Social Sciences. (7th edition) Bangkok: Educational Testing Center andPsychology. SrinakharinwirotUniversity.

VichanPanich. (2007). Contemplation : Educationas a path of spiritual pursuit.SpiritBangkok: SuanNguenMee Ma. 